CLINICAL STUDY

\title{
Influence of prematurity and growth restriction on the adipokine profile, IGF 1, and ghrelin levels in cord blood: relationship with glucose metabolism
}

\author{
Gabriel Á Martos-Moreno ${ }^{1,2,3}$, Vicente Barrios ${ }^{1,2,3}$, Miguel Sáenz de Pipaón ${ }^{4}$, Jesús Pozo ${ }^{1,2,3}$, Izaskun Dorronsoro ${ }^{4}$, \\ Miriam Martínez-Biarge ${ }^{4}$, José Quero ${ }^{4}$ and Jesús Argente ${ }^{1,2,3}$ \\ ${ }^{1}$ Department of Endocrinology, Hospital Infantil Universitario Niño Jesús, Universidad Autónoma de Madrid, E-28009 Madrid, Spain, ${ }^{2}$ Department of \\ Pediatrics, Hospital Infantil Universitario Niño Jesús, Avenida Menéndez Pelayo, 65, E-28009 Madrid, Spain, ${ }^{3}$ CIBER Fisiopatología Obesidad y Nutrición \\ (CIBERobn), Instituto de Salud Carlos III, E-28009 Madrid, Spain and ${ }^{4}$ Department of Neonatology, Hospital Infantil Universitario La Paz, Universidad \\ Autónoma de Madrid, E-28049 Madrid, Spain
}

(Correspondence should be addressed to J Argente; Email: argentefen@terra.es)

\begin{abstract}
Objective: To determine the influence of gestational age and fetal growth restriction on the cord blood adipokine profile, IGF1, and ghrelin levels, and their relationship with glucose metabolism.

Study design: One hundred and ninety newborns (99 preterm and 91 full term) were studied and, according to their anthropometry at birth, classified as small (SGA) or adequate for gestational age (AGA).

Methods: Venous cord blood serum levels of IGF1, IGF binding protein 3 (IGFBP-3), adiponectin, resistin, leptin, soluble leptin receptor (sOB-R), tumoral necrosis factor- $\alpha$, interleukin 6 (IL-6), total ghrelin, and acylated ghrelin were determined and compared between preterm and full-term, as well as between SGA and AGA, newborns. Correlations with newborn weight, gestational age, and homeostatic model assessment (HOMA) index, as an index of insulin resistance, were determined. Results: Preterm newborns had higher HOMA, sOB-R, resistin, and IL-6 and lower IGF1, IGFBP-3, leptin, and adiponectin levels than full-term newborns. SGA had lower IGF1, IGFBP-3, leptin, IL-6, and adiponectin and higher sOB-R and total ghrelin than AGA newborns. Adiponectin and HOMA showed independent positive and negative correlations with gestational age respectively, but not with neonatal weight. Birth weight was correlated positively with IGF1 and leptin levels and negatively with total ghrelin ones.

Conclusions: Our findings suggest that the lack of proper acquisition of adipose tissue by the fetus either due to prematurity or to fetal growth restriction is associated with changes in the cord blood adipokine profile that may contribute to the impairment of glucose metabolism.
\end{abstract}

European Journal of Endocrinology 161 381-389

\section{Introduction}

Adipokines, peptides produced mainly by adipose tissue (AT), in addition to peptides produced from the digestive tract, play critical roles in energy homeostasis and metabolic regulation. Thus, the interest in AT as an active player in energy balance control has substantially increased in recent years $(1,2)$.

Intrauterine life is an especially interesting developmental stage, as fetal AT maturation, mainly taking place in the second trimester of gestation, and its later accumulation during the third trimester (3) are key factors for the correct functionality of this tissue. AT is essential for lipid and, more importantly, glucose metabolism, as the latter is severely impaired in lipodystrophy when AT is lacking, as well as in obesity when there is an excess (4). The adipokine expression profile evolves in parallel with adipogenic cellular maturation; thus, leptin is secreted in late stages and adiponectin only by fully differentiated adipocytes (5). Hence, fetal serum adipokine levels are potential markers of the degree of development and amount of AT, which determine adipokine secretion rate and, thus, potential physiological activity.

Adipokines are secreted by both adipocytes and the mononuclear cells in the stromal vascular fraction of AT (1). Among these, leptin and adiponectin are mainly, if not specifically (adiponectin), produced by adipocytes with their synthesis and release rates influenced by adipocyte morphology, functional status, and triglyceride content $(1,2)$. These two adipokines act through specific receptors on target tissues, while a circulating soluble leptin receptor (sOB-R) is suggested to modulate leptin signaling (6). Indeed, the leptin/sOB-R system is a 
key element in energy homeostasis, constituting the main peripheral signal of AT accumulation (1). Adiponectin plays an important role in carbohydrate metabolism, favoring peripheral insulin-induced glucose uptake (2), although precise evidence of this role in the fetal period is lacking.

Resistin, interleukin 6 (IL-6), and tumoral necrosis factor- $\alpha(\mathrm{TNF}-\alpha)$ represent some of the proinflammatory adipokines released by AT. These factors are mainly produced by mononuclear cells in the adipose stromal fraction (7) and are assumed to act primarily in an auto- or paracrine fashion. However, AT contributes significantly to the circulating levels of some proinflammatory adipokines, for example IL- 6 , where up to one-third of its circulating levels is derived from AT (2). In vitro and in vivo studies in later stages of life have shown how these proinflammatory molecules are involved in the development of resistance to insulininduced glucose uptake (8).

The role of insulin-like growth factors (IGFs) and their binding proteins (IGFBPs), mainly produced by the liver, in prenatal growth is well known (9). The oxyntic cells in the stomach mucosa are the main source of ghrelin, which acts as an endogenous secretagogue of $\mathrm{GH}$ and also plays a major role in hypothalamic control of energy homeostasis (2). Ghrelin undergoes posttransductional Ser3 octanoylation to produce acyl ghrelin, with ability to bind its specific GHS-1A receptor in the hypothalamus and peripheral tissues (10). This influence of ghrelin on energy homeostasis and the GH/IGF axis raises the possibility of its involvement in prenatal growth.

Gestational age and prenatal growth play a fundamental role in AT maturation and accumulation, which influence the adipokine secretion profile. Thus, both prematurity and fetal growth restriction interfere with the correct acquisition of AT by the fetus and could disturb its metabolic functions and endocrine secretions, thereby limiting the metabolic adaptation of premature or fetal growth-restricted newborns to extrauterine life. Indeed, the minimal AT existing in extremely preterm or growth-restricted infants seems to contribute to the generation of insulin resistance and impaired carbohydrate metabolism, making insulin therapy often necessary (11). Moreover, children born preterm or small for gestational age (SGA) are prone to the development of obesity, insulin resistance, and associated metabolic disturbances in later stages of life (12).

Our aims in this study were: i) to evaluate the influence of gestational age on AT maturation and accumulation by simultaneously comparing IGF1, IGFBP-3, leptin, sOB-R, adiponectin, resistin, TNF- $\alpha$, IL-6, and total and acylated ghrelin cord blood serum levels between preterm (PTN) and full-term newborns (FTN); ii) to study the influence of fetal growth restriction on the development of AT by comparing the same parameters between infants born SGA or with an anthropometry adequate for gestational age (AGA); iii) to analyze the relationships between adipokine and ghrelin levels and glucose and insulin concentrations and homeostatic model assessment (HOMA) index.

\section{Patients and methods}

Venous cord blood samples from 190 newborns (95 females and 95 males) were collected in the Department of Neonatology of the Hospital Infantil Universitario La Paz (Madrid, Spain). According to their gestational age at delivery, $91(47.9 \%)$ were FTN (gestational age $\geq 37$ weeks; mean $39.28 \pm 1.14$, range 37.0-41.4 weeks) and $99(52.1 \%)$ were PTN (gestational age < 37 weeks; mean 29.14 \pm 2.99 ; range 22.0-36.0 weeks), with 78 out of the 99 PTNs (79\%) below 32 weeks of gestational age. All babies were born after uncomplicated pregnancies and were otherwise healthy. Birth weight and length at delivery were recorded and standardized according to national references (13). No anthropometric standards were available for infants below 26 weeks gestational age $(n=13)$, and exclusively raw data were used in these cases. Rohrer's ponderal index was calculated as weight $(\mathrm{g}) \times 100 /(\text { length }(\mathrm{cm}))^{3}$.

Those newborns from single pregnancies whose birth weight and/or length were below -2 SDS for gestational age and sex were classified as SGA for later comparison with AGA newborns $(n=141)$. Out of the 190 newborns, 29 (15.3\%) matched the criteria for SGA diagnosis according to their weight $(n=3)$, length $(n=19)$, or both $(n=7)$. Twenty-two SGA newborns were PTN (75.9\%) and seven were FTN (24.1\%). Only seven babies were classified as large for gestational age (weight or length $>2$ SDS). The characteristics of the studied population are detailed in Table 1.

All parents were informed about the purpose of the study and gave informed consent as required by the local ethics committee, which had previously approved the study.

\section{Biochemical measurements}

Blood glucose concentration was immediately quantified, whereas serum specimens were collected after the blood sample was allowed to clot and centrifuged at $4{ }^{\circ} \mathrm{C}$. Serum was collected in a dry tube, separating and acidifying an aliquot in an independent tube according to the manufacturer's instructions for acylated ghrelin determination (LINCO Research, Inc., St Charles, MO, USA) and then storing both tubes at $-80{ }^{\circ} \mathrm{C}$ until assayed. Commercial RIA from LINCO Research, Inc. were used to measure insulin, leptin, adiponectin, total, and acylated ghrelin levels, and from Mediagnost Inc. (Reutlingen, Germany) to determine IGF1 and IGFBP-3 levels. Commercial enzyme immunoassays were used to quantify sOB-R (Biovendor, Brno, Czech Republic), resistin (LINCO Research, Inc.), IL-6, and TNF- $\alpha$ 
Table 1 Group distribution and anthropometric characteristics of the studied population. Results are expressed as mean \pm s.D.

\begin{tabular}{|c|c|c|c|c|c|}
\hline & $\begin{array}{l}\text { Gestational age } \\
\text { (weeks) }\end{array}$ & Weight $(\mathrm{g})$ & Length (cm) & SGA prevalence & Gender (female/male) \\
\hline $\begin{array}{l}\text { Studied cohort } \\
n=190\end{array}$ & $34.00 \pm 5.57$ & $2175 \pm 1195$ & $42.80 \pm 7.22$ & $n=29(15.3 \%)$ & $95 / 95$ \\
\hline $\begin{array}{l}\text { Preterm } \\
n=99 \\
\text { Full term }\end{array}$ & $29.14 \pm 2.99$ & $1130 \pm 341$ & $36.69 \pm 4.05$ & $n=22(22.2 \%)$ & $50 / 49$ \\
\hline$n=91$ & $39.28 \pm 1.14$ & $3325 \pm 583$ & $49.44 \pm 2.43$ & $n=7(7.7 \%)$ & $45 / 46$ \\
\hline
\end{tabular}

(Quantikine HS; R\&D Systems, Inc., Minneapolis, MN, USA) levels, following the manufacturer's protocols and as previously reported $(14,15)$. Sensitivity limit, intra-, and interassay variation coefficients for each peptide were as follows: leptin $(0.5 \mathrm{ng} / \mathrm{ml} ; 4.8$ and $4.5 \%)$; sOB-R $(0.4 \mathrm{ng} / \mathrm{ml} ; 8.4$ and $6.7 \%)$; adiponectin $(1 \mu \mathrm{g} / \mathrm{ml} ; 3.8$ and $9.8 \%)$; resistin $(0.16 \mathrm{ng} / \mathrm{ml} ; 4.5$ and $7.4 \%)$; IL-6 $(0.04 \mathrm{pg} / \mathrm{ml} ; 7.4$ and $7.8 \%)$; TNF- $\alpha(0.12 \mathrm{pg} / \mathrm{ml} ; 6.6$ and $10 \%)$; total ghrelin $(93 \mathrm{pg} / \mathrm{ml} ; 6.4$ and $9.8 \%)$; acylated ghrelin $(7.8 \mathrm{pg} / \mathrm{ml} ; 7.4$ and $9.3 \%) ;$ IGF1 (0.1 ng/ml.; 4.8 and 7.4\%); IGFBP-3 (0.5 $\mu \mathrm{g} / \mathrm{ml} ; 7.5$ and $9 \%)$; insulin $(0.2 \mu \mathrm{U} / \mathrm{ml} ; 6.2$ and $8.1 \%)$.

Free leptin index and HOMA index were calculated according to the formulas leptin $(\mathrm{ng} / \mathrm{ml}) / \mathrm{sOB}-\mathrm{R}$ $(\mathrm{ng} / \mathrm{ml})$ and glucose $(\mathrm{mmol} / \mathrm{l}) \times$ insulin $(\mu \mathrm{U} / \mathrm{ml}) / 22.5$ respectively.

\section{Statistical analysis}

All data are reported as the mean \pm s.D. (or SDS for population-standardized parameters). Student's $t$-test was used to compare normal parametric variables, whereas Mann-Whitney's U-test was used for comparison of non-normally distributed variables (IL-6, TNF- $\alpha$, resistin, and acylated ghrelin) between independent groups. The relationships between quantitative variables were studied by correlation analyses (Pearson's $r$ for normally skewed variables and Spearman's $\rho$ for non-normal ones) followed by Bonferroni correction. Partial correlation (controlling for estimated confounding factors) and simple lineal regression analysis were performed when specified. A value of $P<0.05$ was chosen as the level of significance, reducing it according to Bonferroni correction method when applied in correlation analyses. Statistical analyses were performed using SPSS 11.0 software for Windows (MapInfo Corporation, Troy, NY, USA).

\section{Results}

\section{Adipokine and ghrelin levels according to sex}

No differences in any adipokine, total, or acylated ghrelin levels were found between sexes; however, males had higher sOB-R levels than females $(25.39 \pm 15.52$ vs $20.98 \pm 12.37 \mathrm{ng} / \mathrm{ml} ; P<0.05)$.
When the comparison between genders was performed exclusively in FTN, males were found to have higher sOB-R levels $(20.07 \pm 8.54$ vs 14.97 $\pm 5.92 \mathrm{ng} / \mathrm{ml} ; P<0.001)$ and lower leptin levels and free leptin index than females $(9.88 \pm 7.68$ vs 13.62 $\pm 8.55 \mathrm{ng} / \mathrm{ml} ; \quad P<0.05$ and $0.65 \pm 0.62$ vs 1.12 $\pm 0.89 \mathrm{ng} / \mathrm{ml} ; P<0.01$ respectively). When the comparison was performed only for PTN, males showed lower adiponectin levels than females $(7.76 \pm 4.56$ vs $12.45 \pm 8.33 \mu \mathrm{g} / \mathrm{ml} ; \quad P<0.001)$, with neither sexrelated differences in leptin, sOB-R nor in any other adipokine or ghrelin levels.

\section{Adipokine and ghrelin levels according to gestational age}

All of the studied adipokines, acylated and total ghrelin, IGF1, and IGFBP-3 were detectable and their concentration could be quantified at any gestational age (range 22.0-41.4 weeks). When comparing adipokine and ghrelin concentrations between FTN and PTN, we found that PTN had higher sOB-R, resistin, and IL-6 concentrations than FTN, whereas the latter had higher leptin, adiponectin, IGF1 and IGFBP-3 levels, and free leptin index than PTN (Fig. 1). In contrast, no significant differences between PTN and FTN were found in TNF- $\alpha(2.70 \pm 1.36$ vs $2.70 \pm 0.72 \mathrm{pg} / \mathrm{ml})$, total $(1211 \pm 668$ vs $1199 \pm 526 \mathrm{pg} / \mathrm{ml})$, or acylated ghrelin $(146 \pm 97$ vs $137 \pm 100 \mathrm{pg} / \mathrm{ml})$ levels. Additionally, PTN had higher glucose $(72.76 \pm 28.80$ vs $65.28 \pm 15.84 ; \quad P<0.05)$ and insulin levels $(9.25 \pm 12.29$ vs $4.68 \pm 3.86 ; P<0.001)$ as well as HOMA index $(2.29 \pm 4.44$ vs $0.79 \pm 0.87 ; P<0.01)$ than FTN.

Gestational age was positively correlated with leptin, adiponectin, IGF1, and IGFBP-3 levels and negatively correlated with glucose, insulin, resistin, sOB-R and IL-6 levels, and HOMA index, although the significance in the correlation with glucose levels was lost after applying the Bonferroni adjustment. No correlation was found between gestational age and TNF- $\alpha$, total, or acylated ghrelin. When these correlations were performed controlling for the potentially confounding effect of the weight of the newborn in normally distributed variables, gestational age sustained a positive correlation with adiponectin levels (Fig. 2), as (weakly) did with insulin and HOMA (Table 2). 

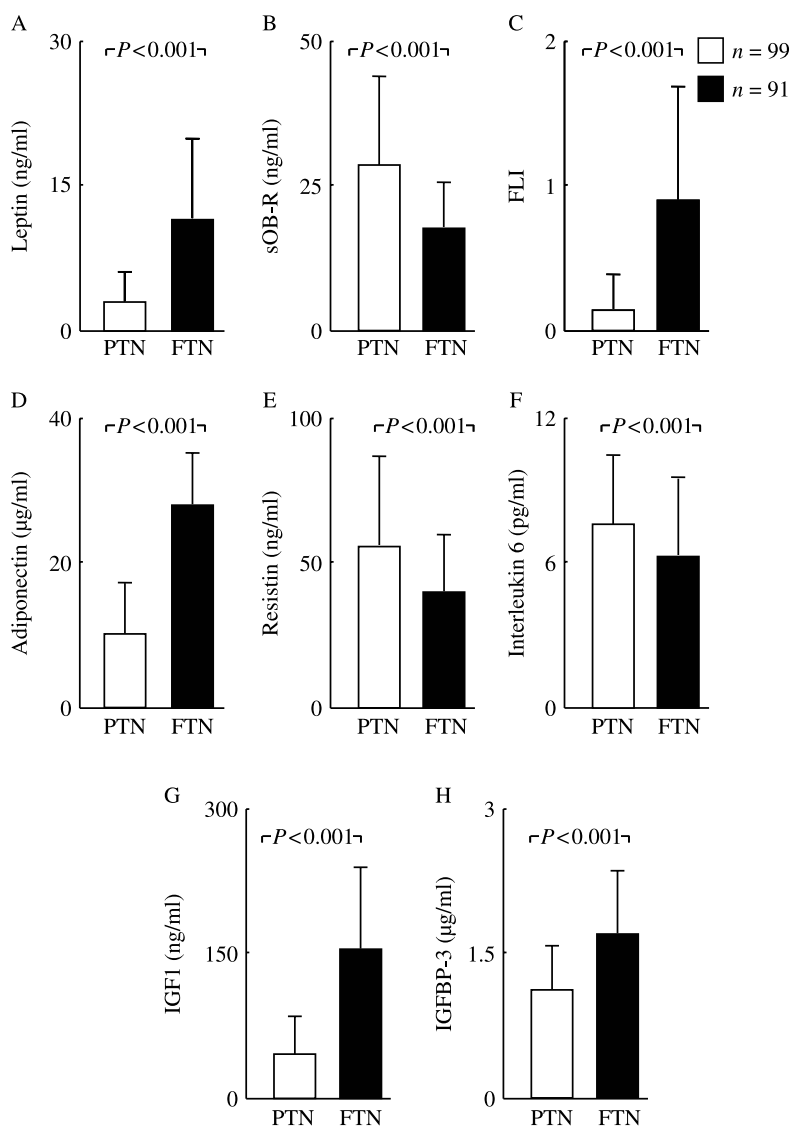

Figure 1 Comparison of leptin, $(A)$, soluble leptin receptor (sOB-R; B), free leptin index (FLI; C), adiponectin (D), resistin $(E)$, interleukin $6(F)$, IGF1 $(G)$, and IGFBP-3 $(H)$ between preterm (PTN) and full-term (FTN) newborns. Data are presented as mean \pm S.D.

A simple linear regression analysis was performed predicting serum adiponectin levels (dependent variable) based on their gestational age (independent variable). A significant regression equation was found $(F(1,185)=398.7, P<0.001)$ with an adjusted $R$ square of 0.683 .

\section{Adipokine and ghrelin levels according to anthropometry}

SGA newborns showed lower levels of IGF1, IGFBP-3, leptin, adiponectin, IL-6, and free leptin index than AGA newborns. In contrast, their sOB-R and total ghrelin levels were higher. No differences between these groups were found in the remaining studied parameters (Fig. 3).

To investigate the eventual correlations between the studied parameters and newborn anthropometry excluding the influence of gestational age, partial correlations controlling for gestational age were studied for ponderal index and weight in normally distributed variables. No significant independent correlation between any of the studied molecules and ponderal index was found after controlling for gestational age.

In contrast, standardized birth weight for GA (SDS) was positively correlated with IGF $1 \quad(r=+0.24$; $P<0.001)$, IGFBP-3 $(r=+0.38 ; P<0.001)$, and leptin $(r=+0.24 ; P<0.001)$, and negatively with sOB-R $(r=-0.25 ; P<0.001)$ and total ghrelin $(r=-0.27$; $P<0.001)$. However, a positive correlation between GA and standardized birth weight (SDS) was observed $(r=+0.23 ; P<0.01)$. Thus, when partial correlation studies, controlling for GA, were performed, newborn weight $(\mathrm{g})$ was independent and positively correlated with IGF1 $(r=+0.29 ; P<0.01)$ and leptin $(r=+0.23$; $P<0.01)$ levels as well as with free leptin index $(r=+0.26 ; \quad P<0.01)$, and negatively correlated with total ghrelin levels $(r=-0.25 ; P<0.01)$. No correlation with newborn weight was found for any of the other peptides studied, or for glucose, insulin and HOMA index.

\section{Correlations between the studied parameters}

Partial correlations between the studied parameters with normal distribution controlling for both gestational age and body weight were performed. IGF1 levels were correlated positively with IGFBP-3 $(r=+0.63$; $P<0.001)$ and negatively with total ghrelin levels $(r=-0.19 ; P<0.05)$. Spearman's $\rho$-test followed by Bonferroni correction showed that also resistin, IL-6, and TNF- $\alpha$ levels showed positive correlations with each other's levels (Table 3). Finally, no significant correlations were found individually between HOMA index, glucose, and insulin levels with any of the studied peptides.

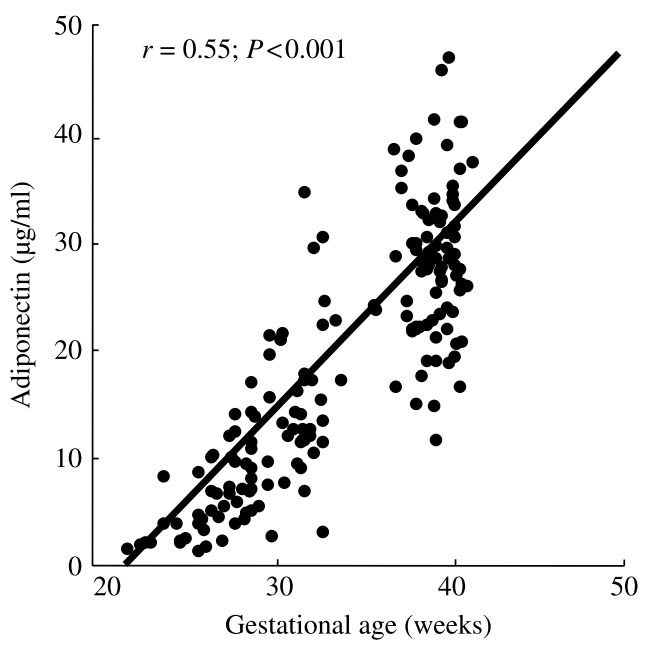

Figure 2 Partial correlation between gestational age and adiponectin levels in venous cord blood, after controlling for birth weight. Correlation coefficient $(r)$ and significance level $(P)$ are shown. 
Table 2 Correlation coefficients (Pearson's $r$ and Spearman's $\rho$ ) and significance levels between gestational age and leptin, soluble leptin receptor (sOB-R), adiponectin, resistin, interleukin 6 (IL-6), insulin, insulin-like growth factor 1 (IGF1), and IGF binding protein 3 (IGFBP-3) levels and HOMA index.

\begin{tabular}{lll}
\hline & \multicolumn{2}{c}{ Gestational age (weeks) } \\
\cline { 2 - 3 } & Raw correlation & Partial correlation \\
\hline Leptin & $r=+0.58 ; P<0.001$ & NS \\
sOB-R & $r=-0.37 ; P<0.001$ & NS \\
Adiponectin & $r=+0.83 ; P<0.001$ & $r=+0.55 ; P<0.001$ \\
Resistin & $\rho=-0.25 ; P<0.001$ & - \\
IL-6 & $\rho=-0.25 ; P<0.001$ & - \\
Insulin & $r=-0.24 ; P<0.001$ & $r=-0.17 ; P<0.05$ \\
HOMA & $r=-0.26 ; P<0.001$ & $r=-0.16 ; P<0.05$ \\
IGF1 & $r=+0.60 ; P<0.001$ & NS \\
IGFBP-3 & $r=+0.44 ; P<0.001$ & NS \\
\hline
\end{tabular}

NS, not significant.

Statistically significant partial correlation coefficients between gestational age and adipokine levels after controlling for birth weight are shown in column 2 .

\section{Discussion}

This study indicates that the studied peptides mainly secreted from AT (adipokines), stomach (ghrelin), and liver (IGF1 and IGFBP-3) are present in cord blood as early as at 22 weeks of fetal life, and that gestational age is a determinant for the adipokine profile in cord blood. Indeed, PTN have higher sOB-R, resistin, and IL-6 levels and lower IGF1, IGFBP-3, leptin, and adiponectin levels than FT newborns, with gestational age being the main predictor of adiponectin levels. Fetal growth restriction also influences these peptides as SGA babies had lower IGF1, IGFBP-3, leptin, IL-6, and adiponectin levels and higher sOB-R and total ghrelin levels than AGA newborns, with neonatal weight correlating positively with IGF1 and leptin levels and negatively with total ghrelin, independently of gestational age. Finally, the negative correlation between HOMA and gestational age, independent of birth weight and the higher HOMA index displayed by PTN, emphasizes the importance of prematurity and AT development in glucose metabolism even in early fetal maturation.

Our findings novelly extend the study of these peptides to a younger gestational age than previous studies, originally showing gender-related differences in the leptin/sOB-R axis status in FTN as in adiponectin levels in early fetal life. This last finding, next to the main effect of gestational age in determining adiponectin levels, suggests a potential role for adiponectin as a marker of the degree of maturation and development of fetal AT.

The increase in leptin levels with the progression of gestation has been postulated as a direct effect of advancing gestational age $(16,17)$; nevertheless, it is thought to be mainly due to the quantitative increase in AT acquisition by the fetus throughout pregnancy $(18-20)$, which is supported by the lower leptin levels and free leptin index found in SGA newborns, as by the positive correlation of leptin levels and free leptin index with birth weight, independently of gestational age (whereas their correlations with gestational age disappeared when controlling for birth weight). Hence, leptin levels may be a better indicator of the amount of AT in the newborn rather than of its level of maturation, as previously suggested (21).

There are contrasting reports concerning the existence of higher cord blood leptin levels in female newborns. Interestingly, the studies showing this sexual dimorphism were performed exclusively in FTN $(19,22)$, whereas it was not found when the studied cohort included PTN (18). Our findings confirm both observations, with no differences in leptin levels found between sexes when the cohort was analyzed as a whole or in PTN separately, but with female FTN having higher leptin and free leptin index than male FTN. Thus, this sexual dimorphism in leptin levels seems to be a late gestational event and, in the absence of differences in weight or ponderal index, points towards a higher fat content in females than in males already in late pregnancy, as shown at birth and throughout extrauterine life $(23,24)$.
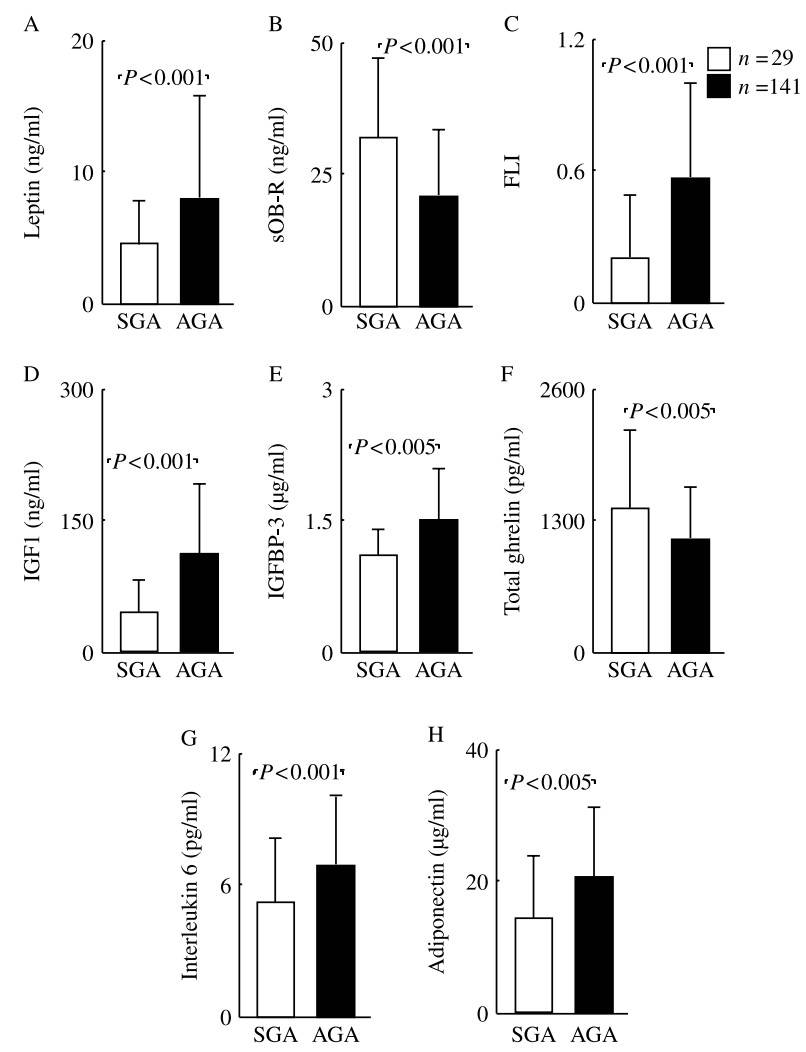

Figure 3 Comparison of leptin (A), leptin soluble receptor (sOB-R; $B$ ), free leptin index (FLI; C), IGF1 (D), IGFBP-3 (E), total ghrelin (F), interleukin $6(G)$, and adiponectin $(H)$ levels between small for gestational age (SGA) and adequate for gestational age (AGA) newborns. Data are shown as mean \pm s.D. 
Table 3 Spearman's $\rho$-test with Bonferroni adjustment for correlation between resistin, interleukin 6 (IL-6), and tumoral necrosis factor- $\alpha$ (TNF- $\alpha$ ) levels.

\begin{tabular}{llll}
\hline & Resistin & IL-6 & TNF- $\alpha$ \\
\hline Resistin & - & $\rho=+0.28 ; P<0.001$ & $\rho=+0.33 ; P<0.001$ \\
IL-6 & $\rho=+0.28 ; P<0.001$ & - & $\rho=+0.22 ; P<0.01$ \\
TNF- $\alpha$ & $\rho=+0.33 ; P<0.001$ & $\rho=+0.22 ; P<0.01$ & - \\
\hline
\end{tabular}

sOB-R levels behave in an opposite fashion to leptin levels at birth (25), as in later stages of extrauterine life (6). The higher sOB-R levels found in SGA newborns are in agreement with this statement and suggest that fetal weight is a main determinant of cord sOB-R levels. The sexual dimorphism for sOB-R observed in FTN was previously reported as a nonsignificant trend (25). However, the higher number of newborns included in our study may explain our observation that FTN males had significantly higher sOB-R levels than females, which reinforces the hypothesis of enhanced leptin availability and body fat content in female FTN.

The changes in leptin and sOB-R levels result in an increase in leptin bioavailability during the final stages of the gestation, in parallel with IGF1 and IGFBP-3 levels. This has been suggested to be a signal of adequate weight gain $(20,26)$. The positive independent correlation of IGF1 with neonatal weight and the lower IGF1 and IGFBP-3 levels in SGA compared with AGA newborns found confirm previous reports by our group (9), and reinforce the postulated role of these peptides in prenatal growth control. Moreover, the leptin axis could already be acting as a self-control mechanism to avoid excessive fetal growth at the end of the pregnancy, with the low free leptin index found in SGA newborns constituting an adaptive mechanism to fetal growth restriction.

Total ghrelin levels did not differ between sexes or between PTN and FTN and no correlation with gestational age was found, which confirms reports from our group (27) and others (28-30). Here, we extend this finding to a wider gestational age, as a high number of newborns below 32 weeks of gestational age were included in this study. In addition, we confirm the previously reported negative correlation between total ghrelin levels and birth weight $(27,28)$, which remained significant when PTN and FTN were studied separately. Furthermore, total ghrelin levels were higher in SGA and had a weak but significant negative partial correlation with IGF1 levels. Together, these data suggest that ghrelin already has a functional role in late pregnancy, acting to favor a positive energy balance under fetal growth restriction, and that total ghrelin levels are regulated through a negative feedback system by fetal weight and, maybe, IGF1 (31).

Acylated ghrelin levels did not differ between sexes, PTN and FTN, and SGA and AGA newborns, with no correlations observed between acylated ghrelin levels and gestational age, birth weight, length, or ponderal index, as previously reported (32). The negative correlation previously described between acylated ghrelin and IGF1 levels in FTN (33) disappeared when controlling for either gestational age or birth weight. A precise role for acylated ghrelin during pregnancy remains unknown, although the early changes in acylated ghrelin levels that occur after birth in PTN (34) suggest a possible role for acylated ghrelin in the adaptation of the newborn's metabolism to extrauterine life.

We demonstrate that gestational age has the greatest influence on cord blood adiponectin levels, ratifying previous reports (35). Indeed, the lack of correlation between adiponectin and birth weight when controlling for the effect of gestational age strongly suggests that gestational age has a greater effect than fetal weight $(36,37)$ on cord blood adiponectin levels. As adiponectin is only produced by mature adipocytes and not by its precursors (5), these results suggest that this peptide may be the first reliable marker of AT maturation.

Nevertheless, the low adiponectin levels found in SGA newborns in our cohort and by others (38) and the fact that the increase in its levels occurs during the third trimester, coincident with AT accumulation, do not allow the increase in adiponectin levels to be attributed exclusively to fetal maturation, thus suggesting that the increase in fetal weight also influences cord blood adiponectin levels. This increase in adiponectin levels with fat mass gain is opposite to that described in adults (39), indicating that the negative influence of fat mass on adiponectin secretion must be absent in the fetus. This could favor the relatively higher adiponectin levels when compared with adults and could be beneficial for fetal glucose disposal due to the insulin-sensitizing effect of adiponectin, although this effect remains to be fully established in intrauterine life. The mechanisms regulating fetal adiponectin secretion are unknown, although the lower body fat content of the newborn compared with children or adults and the limited adipocyte hypertrophy and predominant increase in adipocyte number in the newborns have been suggested as possible causes of these differential dynamics of serum adiponectin in the newborn (40).

In FTN no gender differences in cord blood adiponectin levels were found in accordance with previous reports (40). In contrast, female PTN had significantly higher adiponectin levels compared with their male counterparts. This could suggest that maturation of AT 
may begin earlier in females, conferring them a more precocious ability for metabolic adaptation to preterm delivery over males, which could favor their survival rate $(41,42)$. The very recent finding of higher high molecular weight adiponectin levels in female FTN cord blood compared with males could be another indication of advantages of females regarding the acquisition and functionality of AT during gestation (43).

The higher resistin levels found in PTN contrast with the results by $\mathrm{Ng}$ et al. (44), although they are not directly comparable as the latter come from post-natally collected samples. Our data are consistent with those in the literature showing higher resistin concentrations in cord blood than in adulthood, with stress and infections proposed as possible causes for these differences $(45,46)$. As resistin stimulates IL-6 and TNF- $\alpha$ synthesis (47), the positive correlation found between these three molecules could indicate their parallel increase in a proinflammatory environment. Furthermore, as there are no differences in resistin levels between SGA and AGA newborns (48) and its levels show no correlation with weight or parameters of carbohydrate metabolism, it is difficult to speculate on any other specific role for resistin in fetal physiology.

As IL- 6 and TNF- $\alpha$ are involved in immune mechanisms, both stress and infection highly influence their serum levels (49). Interestingly, the innate immunity of the human newborn is polarized toward a high ratio of IL-6/TNF- $\alpha$ production (50). This could underlie the differences in IL- 6 levels between PTN and FTN found in our cohort, as well as in a previous report (16), whereas no differences in TNF- $\alpha$ levels were seen. In addition, the lower IL-6 levels in SGA regarding AGA infants might be related to their lower fat content, as AT produces up to the $30 \%$ of circulating IL- 6 (2).

The higher glucose and insulin levels and HOMA in PTN and the negative correlation between HOMA and insulin levels and gestational age, independently of birth weight, are in agreement with a degree of insulin resistance associated to prematurity. This could be due to the reduced amount and immaturity of their AT. Thus, as occurs in pathological lipodystrophies where AT is greatly reduced, higher insulin levels are required to induce glucose caption by peripheral tissues, suggesting a situation of 'physiological lipodystrophy' in PTN. This could help to explain why insulin infusion is sometimes necessary to stabilize glycemia in PTN $(11,51)$. Newborns have greater fluctuations in glucose and insulin levels compared with adults; this could explain the weak correlation coefficients found between gestational age, insulin, and HOMA index, and the lack of correlations between HOMA and any of the adipokines or ghrelin levels. Moreover, despite that a previous report did not find differences in cord blood insulin levels when considering possible maternal and/or fetal stress confounders (mode and urgency of delivery, infection, or fetal distress) (52), our study does not allow us to rule out their possible effect on cord blood glucose and insulin levels, and they could influence the distribution observed in the parameters of carbohydrate metabolism.

In summary, our results demonstrate that both gestational age and newborn weight are major determinants of cord blood adipokine profile, whereas fetal growth restriction also influences ghrelin levels. In addition, we have shown how adiponectin levels are mainly determined by gestational age, whereas the influence of birth weight is greater on the leptin and IGF1 axes. Furthermore, the higher adiponectin levels and leptin availability found in PTN and FTN females respectively suggest earlier maturation of the AT in female fetuses and greater later acquisition regarding males. Finally, the shortage and immaturity of AT in PTN determine a situation of physiological lipodystrophy, which could favor insulin resistance in prematurity. On the basis of these findings, we can conclude that the lack of proper acquisition of AT by the fetus either in prematurity or in fetal growth restriction is associated with changes in the cord blood adipokine profile and ghrelin levels that may impair their glucose metabolism and metabolic adaptation to extrauterine life.

\section{Declaration of interest}

The authors declare that there is no conflict of interest that could be perceived as prejudicing the impartiality of the research reported.

\section{Funding}

This work was supported by the 'CIBER Fisiopatología de la Obesidad y Nutrición' (CB03/06) and by the 'Fondo de Investigación Sanitaria' (grant number PI041631). G A Martos-Moreno is a recipient of a 'Contrato Rio Hortega' from the 'Instituto de Salud Carlos III' (FIS CM05/00100).

\section{Acknowledgements}

The authors would like to acknowledge Dr Julie Chowen for her critical review of the manuscript.

\section{References}

1 Kershaw EE \& Flier JS. Adipose tissue as an endocrine organ. Journal of Clinical Endocrinology and Metabolism $2004 \mathbf{8 9}$ 2548-2556.

2 Meier U \& Gressner AM. Endocrine regulation of energy metabolism: review of pathobiochemical and clinical chemical aspects of leptin, ghrelin, adiponectin, and resistin. Clinical Chemistry 200450 1511-1525.

3 Symonds ME, Mostyn A, Pearce S, Budge H \& Stephenson T. Endocrine and nutritional regulation of fetal adipose tissue development. Journal of Endocrinology 2003179 293-299.

4 Rosen ED \& Spiegelman BM. Adipocytes as regulators of energy balance and glucose homeostasis. Nature $2006444847-853$.

5 Körner A, Wabitsch M, Seidel B, Fischer-Posovszky P, Berthold A, Stumvoll M, Blüher M, Kratzsch J \& Kiess W. Adiponectin expression in humans is dependent on differentiation of adipocytes and down-regulated by humoral serum components of high molecular weight. Biochemical and Biophysical Research Communications 2005337 540-550. 
6 Kratzsch J, Lammert A, Bottner A, Seidel B, Mueller G, Thiery J, Hebebrand J \& Kiess W. Circulating soluble leptin receptor and free leptin index during childhood, puberty, and adolescence. Journal of Clinical Endocrinology and Metabolism 200287 4587-4594.

7 Fain JN. Release of interleukins and other inflammatory cytokines by human adipose tissue is enhanced in obesity and primarily due to the nonfat cells. Vitamins and Hormones $2006 \mathbf{7 4} 443-477$.

8 Tilg H \& Moschen AR. Inflammatory mechanisms in the regulation of insulin resistance. Molecular Medicine 200814 222-231.

9 Barrios V, Argente J, Pozo J, Hervás F, Muñoz MT, Sánchez JI \& Hernández M. Insulin-like growth factor I, insulin-like growth factor binding proteins, and growth hormone binding protein in Spanish premature and full-term newborns. Hormone Research 199646 130-137.

10 Kojima M, Hosoda H, Date Y, Nakazato M, Matsuo H \& Kangawa K. Ghrelin is a growth-hormone-releasing acylated peptide from stomach. Nature $1999 \mathbf{4 0 2} 656-660$.

11 Leipälä JA, Raivio KO, Sarnesto A, Panteleon A \& Fellman V. Intrauterine growth restriction and postnatal steroid treatment effects on insulin sensitivity in preterm neonates. Journal of Pediatrics $2002141472-476$.

12 Rotteveel J, van Weissenbruch MM, Twisk JW \& Delemarre-Van de Waal HA. Infant and childhood growth patterns, insulin sensitivity, and blood pressure in prematurely born young adults. Pediatrics 2008122 313-321.

13 Carrascosa Lezcano A, Ferrández Longás A, Yeste Fernández D, García-Dihinx Villanova J, Romo Montejo A, Copil Copil A, Almar Mendoza J, Salcedo Abizanda S, Gussinyé Canadell M \& Baguer Mor L. Estudio transversal español de crecimiento 2008. Parte I: valores de peso y longitud en recién nacidos de 26-42 semanas de edad gestacional. Anales de Pediatría 200868 544-551.

14 Martos-Moreno GÁ, Barrios V \& Argente J. Normative data for adiponectin, resistin, interleukin 6 , and leptin/receptor ratio in a healthy Spanish pediatric population: relationship with sex steroids. European Journal of Endocrinology 2006155 429-434.

15 Martos-Moreno GÁ, Barrios V, Soriano-Guillén L \& Argente J. Relationship between adiponectin levels, acylated ghrelin levels, and short-term body mass index changes in children with diabetes mellitus type 1 at diagnosis and after insulin therapy. European Journal of Endocrinology 2006155 757-761.

16 Lo HC, Tsao LY, Hsu WY, Chen HN, Yu WK \& Chi CY. Relation of cord serum levels of growth hormone, insulin-like growth factors, insulin-like growth factor binding proteins, leptin, and interleukin- 6 with birth weight, birth length, and head circumference in term and preterm neonates. Nutrition 200218 604-608.

17 Stoll-Becker S, Kreuder J, Reiss I, Etspüler J, Blum WF \& Gortner L. Influence of gestational age and intrauterine growth on leptin concentrations in venous cord blood of human newborns. Klinische Padiatrie 2003215 3-8.

18 Shekhawat PS, Garland JS, Shivpuri C, Mick GJ, Sasidharan P, Pelz CJ \& McCormick KL. Neonatal cord blood leptin: its relationship to birth weight, body mass index, maternal diabetes, and steroids. Pediatric Research 199843 338-343.

19 Ong KK, Ahmed ML, Sherriff A, Woods KA, Watts A, Golding J \& Dunger DB. Cord blood leptin is associated with size at birth and predicts infancy weight gain in humans. ALSPAC study team. Avon longitudinal study of pregnancy and childhood. Journal of Clinical Endocrinology and Metabolism 199984 1145-1148.

20 Christou H, Connors JM, Ziotopoulou M, Hatzidakis V, Papathanassoglou E, Ringer SA \& Mantzoros CS. Cord blood leptin and insulin-like growth factor levels are independent predictors of fetal growth. Journal of Clinical Endocrinology and Metabolism 200186 935-938.

21 Lepercq J, Challier JC, Guerre-Millo M, Cauzac M, Vidal H \& Hauguel-de Mouzon S. Prenatal leptin production: evidence that fetal adipose tissue produces leptin. Journal of Clinical Endocrinology and Metabolism 200186 2409-2413.

22 Matsuda J, Yokota I, Iida M, Murakami T, Naito E, Ito M, Shima K \& Kuroda Y. Serum leptin concentration in cord blood: relationship to birth weight and gender. Journal of Clinical Endocrinology and Metabolism $1997 \mathbf{8 2}$ 1642-1644.
23 Greil H. Patterns of sexual dimorphism from birth to senescence. Collegium Antropologicum 200630 637-641.

24 van der Sluis IM, de Ridder MA, Boot AM, Krenning EP \& de Muinck Keizer-Schrama SM. Reference data for bone density and body composition measured with dual energy $\mathrm{X}$ ray absorptiometry in white children and young adults. Archives of Disease in Childhood 200287 341-347.

25 Kratzsch J, Schubring C, Stitzel B, Böttner A, Berthold A, Thiery J \& Kiess W. Inverse changes in the serum levels of the soluble leptin receptor and leptin in neonates: relations to anthropometric data. Journal of Clinical Endocrinology and Metabolism 200590 2212-2217.

26 Vatten LJ, Nilsen ST, Odegård RA, Romundstad PR \& Austgulen R. Insulin-like growth factor I and leptin in umbilical cord plasma and infant birth size at term. Pediatrics 2002109 1131-1135.

27 Soriano-Guillén L, Barrios V, Chowen JA, Sanchez I, Vila S, Ouero J \& Argente J. Ghrelin levels from fetal life through early adulthood: relationship with endocrine and metabolic and anthropometric measures. Journal of Pediatrics 2004144 30-35.

28 Chanoine JP, Yeung LP, Wong AC \& Birmingham CL. Immunoreactive ghrelin in human cord blood: relation to anthropometry, leptin, and growth hormone. Journal of Pediatric Gastroenterology and Nutrition $200235282-286$.

29 Bellone S, Rapa A, Vivenza D, Vercellotti A, Petri A, Radetti G, Bellone J, Broglio F, Ghigo E \& Bona G. Circulating ghrelin levels in newborns are not associated to gender, body weight and hormonal parameters but depend on the type of delivery. Journal of Endocrinological Investigation 200326 RC9-R11.

$30 \mathrm{Ng}$ PC, Lee CH, Lam CW, Chan IH, Wong E \& Fok TF. Ghrelin in preterm and term newborns: relation to anthropometry, leptin and insulin. Clinical Endocrinology 200563 217-222.

31 Farquhar J, Heiman M, Wong AC, Wach R, Chessex P \& Chanoine JP. Elevated umbilical cord ghrelin concentrations in small for gestational age neonates. Journal of Clinical Endocrinology and Metabolism $2003 \mathbf{8 8} 4324-4327$.

32 Pirazzoli P, Lanari M. Zucchini S, Gennari M. Pagotto U, De Iasio R, Pasquali R, Cassio A, Cicognani A \& Cacciari E. Active and total ghrelin concentrations in the newborn. Journal of Pediatric Endocrinology \& Metabolism 200518 379-384.

33 Yokota I, Kitamura S, Hosoda H, Kotani Y \& Kangawa K. Concentration of the $n$-octanoylated active form of ghrelin in fetal and neonatal circulation. Endocrine Journal 200552 271-276.

34 Shimizu T, Kitamura T, Yoshikawa N, Suganuma H, Hisata K, Tanaka K, Shinohara K \& Yamashiro Y. Plasma levels of active ghrelin until 8 weeks after birth in preterm infants: relationship with anthropometric and biochemical measures. Archives of Disease in Childhood. Fetal and Neonatal Edition 200792 F291-F292.

35 Kajantie E, Hytinantti T, Hovi P \& Andersson S. Cord plasma adiponectin: a 20 -fold rise between 24 weeks gestation and term. Journal of Clinical Endocrinology and Metabolism 200489 $4031-4036$

36 Lindsay RS, Walker JD, Havel PJ, Hamilton BA, Calder AA \& Johnstone FD. Scottish multicentre study of diabetes pregnancy. Adiponectin is present in cord blood but is unrelated to birth weight. Diabetes Care 200326 2244-2249.

37 Pardo IM, Geloneze B, Tambascia MA \& Barros-Filho AA. Hyperadiponectinemia in newborns: relationship with leptin levels and birth weight. Obesity Research 200412 521-524.

38 Takaya J, Yamato F, Higashino H \& Kaneko K. Intracellular magnesium and adipokines in umbilical cord plasma and infant birth size. Pediatric Research 200762 700-703.

39 Arita Y, Kihara S, Ouchi N, Takahashi M, Maeda K, Miyagawa J, Hotta K, Shimomura I, Nakamura T, Miyaoka K, Kuriyama H, Nishida M, Yamashita S, Okubo K, Matsubara K, Muraguchi M, Ohmoto Y, Funahashi T \& Matsuzawa Y. Paradoxical decrease of an adipose-specific protein, adiponectin, in obesity. Biochemical and Biophysical Research Communications 1999257 79-83.

40 Sivan E, Mazaki-Tovi S, Pariente C, Efraty Y, Schiff E, Hemi R \& Kanety H. Adiponectin in human cord blood: relation to fetal birth weight and gender. Journal of Clinical Endocrinology and Metabolism $2003 \mathbf{8 8} 5656-5660$. 
41 Ingemarsson I. Gender aspects of preterm birth. British Journal of Obstetrics and Gynaecology $200311034-38$.

42 Di Renzo GC, Rosati A, Sarti RD, Cruciani L \& Cutuli AM. Does fetal sex affect pregnancy outcome? Gender Medicine 2007 4 19-30.

43 Lau SM, Hng TM, de Vries B, McLean M \& Cheung NW. Sexual dimorphism of high molecular weight adiponectin in cord blood. Clinical Endocrinology 2009 70 500-501.

44 Ng PC, Lee CH, Lam CW, Chan IH, Wong E \& Fok TF. Resistin in preterm and term newborns: relation to anthropometry, leptin, and insulin. Pediatric Research 200558 725-730.

45 Cho GJ, Yoo SW, Hong SC, Oh MJ, Kim T, Kim HJ, Lee KW \& Kin SH. Correlations between umbilical and maternal serum resistin levels and neonatal birth weight. Acta Obstetricia et Gynecologica Scandinavica 200685 1051-1056.

46 Cortelazzi D, Corbetta S, Ronzoni S, Pelle F, Marconi A, Cozzi V, Cetin I, Cortelazzi R, Beck-Peccoz P \& Spada A. Maternal and foetal resistin and adiponectin concentrations in normal and complicated pregnancies. Clinical Endocrinology 200766 447-453.

47 Bokarewa M, Nagaev I, Dahlberg L, Smith U \& Tarkowski A. Resistin, an adipokine with potent proinflammatory properties. Journal of Immunology $2005 \mathbf{1 7 4} 5789-5795$.

48 Briana DD, Boutsikou M, Baka S, Gourgiotis D, Marmarinos A, Hassiakos D \& Malamitsi-Puchner A. Perinatal changes of plasma resistin concentrations in pregnancies with normal and restricted fetal growth. Neonatology 200893 153-157.

49 Kowalik K, Czeszyńska MB \& Celewicz Z. Evaluation of diagnostic usefulness of the cord blood TNF-alpha levels as a marker of early onset neonatal infection. Ginekologia Polska $2003 \mathbf{7 4}$ 439-445.

50 Angelone DF, Wessels MR, Coughlin M, Suter EE, Valentini P, Kalish LA \& Levy O. Innate immunity of the human newborn is polarized toward a high ratio of IL-6/TNF-alpha production in vitro and in vivo. Pediatric Research $200660205-209$.

51 Beardsall K \& Dunger D. Insulin therapy in preterm newborns. Early Human Development $2008 \mathbf{8 4} 839-842$.

52 Chiesa C, Osborn JF, Haass C, Natale F, Spinelli M, Scapillati E, Spinelli A \& Pacifico L. Ghrelin, leptin, IGF-1, IGFBP-3, and insulin concentrations at birth: is there a relationship with fetal growth and neonatal anthropometry? Clinical Chemistry $2008 \mathbf{5 4}$ 550-558.

Received 23 June 2009

Accepted 26 June 2009 